\title{
FIRST RESULTS FROM THE GERMAN CAL/VAL ACTIVITIES FOR AEOLUS
}

\author{
Holger Baars ${ }^{*}$, Alexander Gei ${ }^{2}$, Ulla Wandinger ${ }^{1}$, Alina Herzog ${ }^{1}$, Ronny Engelmann ${ }^{1}$, Johannes \\ Bühl $^{1}$, Martin Radenz ${ }^{1}$, Patric Seifert ${ }^{1}$, Albert Ansmann ${ }^{1}$, Anne Martin ${ }^{2}$, Ronny Leinweber ${ }^{3}$, \\ Volker Lehmann ${ }^{3}$, Martin Weissmann ${ }^{4}$, Alexander Cress ${ }^{4}$, Maria Filioglou ${ }^{5}$, Mika Komppula ${ }^{5}$, \\ and Oliver Reitebuch ${ }^{6}$
}

\author{
${ }^{1}$ Leibniz Institute for Tropospheric Research (TROPOS), Leipzig, Germany \\ ${ }^{2}$ Ludwig-Maximilians-University Munich, Meteorological Institute, Munich, Germany \\ ${ }^{3}$ Deutscher Wetterdienst, Richard-Aßmann-Observatorium, Tauche, Germany \\ ${ }^{4}$ Deutscher Wetterdienst, Offenbach, Germany \\ ${ }^{5}$ Finnish Meteorological Institute, Atmospheric Research Centre of Eastern Finland, Finland \\ ${ }^{6}$ Deutsches Zentrum für Luft- und Raumfahrt e.V., DLR, Institute of Atmospheric Physics, \\ Oberpfaffenhofen, Germany
}

*Email: baars@tropos.de

\begin{abstract}
On 22nd August 2018, the European Space Agency (ESA) launched the first direct detection Doppler wind lidar into space. Operating at 355 $\mathrm{nm}$ and acquiring signals with a dual channel receiver, it allows wind observations in clear air and particle-laden regions of the atmosphere. Furthermore, particle optical properties can be obtained using the High Spectral Resolution Technique Lidar (HSRL) technique. Measuring with $87 \mathrm{~km}$ horizontal and $0.25-2 \mathrm{~km}$ vertical resolution between ground and up to $30 \mathrm{~km}$ in the stratosphere, the global coverage of Aeolus observations shall fill gaps in the global observing system and thus help improving numerical weather prediction. Within this contribution, first results from the German initiative for experimental Aeolus validation are presented and discussed. Ground-based wind and aerosol measurements from tropospheric radar wind profilers, Doppler wind lidars, radiosondes, aerosol lidars and cloud radars are utilized for that purpose.
\end{abstract}

\section{INTRODUCTION}

ESA launched the Earth Explorer Mission Aeolus on 22 August 2018. This mission aims to demonstrate significant improvements in weather forecasting by measuring height-resolved wind profiles in the troposphere and lower stratosphere. ALADIN (Atmospheric Laser Doppler Instrument) is the first Lidar (Light Detection and Ranging) instrument on a European satellite. It is also the first space-borne instrument capable of measuring vertical profiles of wind on a global basis. Next to wind measurements, aerosol properties can be obtained as a spin-off product via the HSRL technique, which is a space-borne novelty as well.

Within the German initiative EVAA (Experimental Validation and Assimilation of Aeolus observations), Calibration/Validation $(\mathrm{Cal} / \mathrm{Val})$ activities of this space mission have been performed by Ludwig-MaximiliansUniversity of Munich (LMU), Leibniz Institute of Tropospheric Research (TROPOS), German Weather Service (DWD) and DLR (Deutsches Zentrum f. Luft- und Raumfahrt). The aim of EVAA is to validate the wind and aerosol products of Aeolus and to quantify the benefits of these new measurements for weather forecasting by assimilation experiments.

For this purpose, validation measurements with aerosol lidar, Doppler cloud radar, wind lidar and radar wind profiler have been performed since Aeolus launch. Four radar wind profiler stations in Germany have been used (e.g. [1]) as well as aerosol and wind lidar observations at Leipzig, Germany and Punta Arenas, Chile. Furthermore, lidar data at the PollyNET [2] locations of Haifa, Israel and in the United Arab Emirates (UAE) are used. 


\section{WIND LIDAR MISSION AEOLUS}

The instrument onboard Aeolus is called ALADIN, a High Spectral Resolution Lidar operating at a wavelength of ca. $355 \mathrm{~nm}$. The laser pulses are emitted with a frequency of $50.5 \mathrm{~Hz}$ and have a circular polarization. More technical details can be found e.g. in [3] and [4].

Aeolus has a weekly repeating polar, sunsynchronous orbit at an inclination of $97^{\circ}$ and a mean altitude of $320 \mathrm{~km}$. Aeolus flies along the day/night border facing towards the night to minimize the background radiation. Thus, the measured Line-of-Sight (LOS) wind is mainly oriented either to the west or to the east.

The mission requirements for the Aeolus Mission are a vertical resolution of $500 \mathrm{~m}$ in the planetary boundary layer $(\mathrm{PBL}), 1 \mathrm{~km}$ in the troposphere and $2 \mathrm{~km}$ in the lower stratosphere. The precision of the horizontal component of LOS (HLOS) was required to be within $1 \mathrm{~m} / \mathrm{s}$ for the PBL, $2.5 \mathrm{~m} / \mathrm{s}$ for the troposphere and $3 \mathrm{~m} / \mathrm{s}$ for the lower stratosphere.

As ALADIN is a high-spectral resolution lidar, having a Rayleigh and Mie channel, it can obtain the extinction and the backscatter coefficient independently as spin-off products. It's the first time that the lidar ratio can be directly measured from space. However, due to the optical architecture of ALADIN which has the same telescope for the outgoing and the receiving signal, only the co-polar component of the circular polarized outgoing light which was backscattered in the atmosphere can be detected. For strongly depolarizing particles, like ice crystals, desert dust or volcanic ash, a significant cross-polar component will thus not be detected. This results in an underestimation of the backscatter coefficient and therefore an overestimation of the lidar ratio [5].

\section{FIRST CAL/VAL EFFORTS}

After first promising results soon after launch, calibration and validation of Aeolus products becomes an essential part of the satellite mission. In order to determine and understand observation biases and random errors as well as possible instrument degradation, independent measurements of co-located instruments are necessary.

\subsection{WIND PRODUCTS}

As part of EVAA, ground-based wind measurements have been performed with tropospheric radar wind profilers (RWP), Doppler wind lidars, radiosondes and cloud radars. Especially radar wind profilers using frequencies between 400 and $500 \mathrm{MHz}$, which are able to measure wind up to $16 \mathrm{~km}$ with high accuracy in clear air as well as in regions with particles and clouds, are very well suited for Aeolus comparisons. The German weather service operates $482 \mathrm{MHz}$ radar wind profilers at four sites in Germany on a 24/7 basis which is enough data for first performance statistics. Figure 1 shows a map with the locations of these four wind profilers and the corresponding Aeolus ground tracks from overpasses of one week.

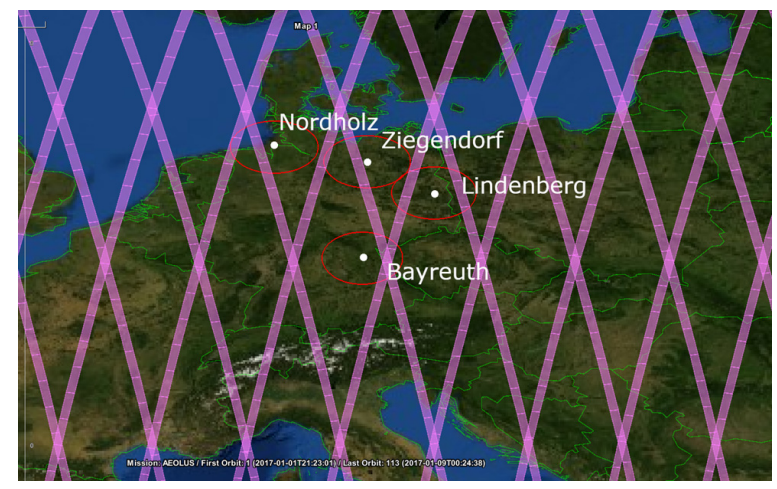

Fig. 1: Map of Central Europe showing the predicted Aeolus ground tracks of one week (magenta) and the four radar wind profiler stations of DWD (white) with a surrounding radius of $100 \mathrm{~km}(\mathrm{red})$.

However, in a comparison of instruments with different spatio-temporal resolution and measurement geometry, thus probing different volumes of the atmosphere, special attention must be paid to the representativeness of both measurements.

First results from comparisons of preliminary Aeolus Level 2B Rayleigh wind observations with radar wind profiler measurements are shown in Figure 2 for the first four months of operation. There is good agreement between both instruments showing a bias of $1.82 \mathrm{~m} / \mathrm{s}$ and a scaled median absolute deviation of $4.75 \mathrm{~m} / \mathrm{s}$. 
From these first preliminary results, it was concluded that the observed Rayleigh wind bias is continuously increasing with time. This is related to the use of ALADIN calibrations from September 2018 for the processing, and thus no instrument alignment drifts are taken into account. With the next product updates, the systematic error characteristics will be improved.

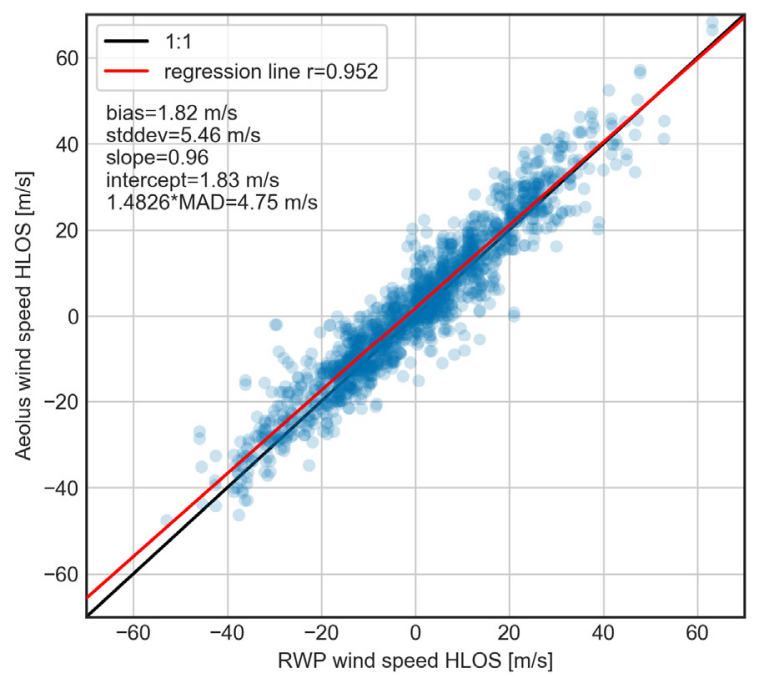

Fig. 2: Comparison of HLOS Rayleigh clear wind speed measured by Aeolus and HLOS projected wind speed from RWP measurements between 04 September 2018 and 15 January 2019. 1630 valid measurements are shown.

\subsection{AEROSOL PRODUCTS}

Aeolus Level 2A data were evaluated against ground-based multiwavelength Raman polarization lidars of type PollyXT [6]. These lidar systems are comprised in a voluntary, scientific network called PollyNET [2]. Fig. 3 shows the current status map of PollyNET. Green circles are active lidar sites while orange points are past campaigns. The yellow circles indicate the locations which have been used for the $\mathrm{Cal} / \mathrm{Val}$ efforts.

For Aeolus Cal/Val, a first focus was laid on homogenous and temporally stable aerosol conditions, best with lofted and high altitude aerosol layers above $2 \mathrm{~km}$. This was requested by ESA during the first data release to the $\mathrm{Cal} / \mathrm{Val}$ teams. For that reason, PollyNET lidar measurements at Haifa, Israel run by TROPOS and near Dubai in UAE run by the Finish
Meteorological Institute (FMI) were considered at first glance.

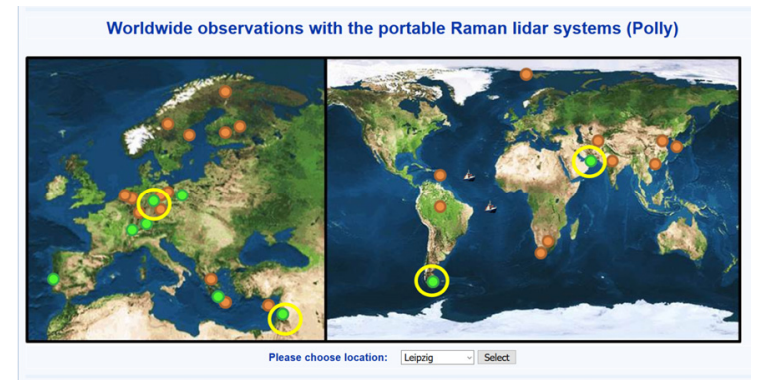

Fig. 3: Map of PollyNET showing active (green) and past (orange) locations. Stations for Aeolus Cal/Val are marked with a yellow circle.

Overpasses in a distance of $100 \mathrm{~km}$ to the groundbased lidar site were analyzed. From the four months of operation until mid of January, about five dedicated scenes with mostly dusty atmosphere at each of the locations could be found, so that in total about 10 suitable comparisons could be made. For the analyses, the prototype Level 2A data have been used, which is so far only accessible for $\mathrm{Cal} / \mathrm{Val}$ teams.

Figure 4 shows one example overpass at Haifa, Israel on $29^{\text {th }}$ September 2018, thus shortly after launch. The PollyXT observations at $355 \mathrm{~nm}$ (thin, black line) were transformed to the co-polar component (thick black line) with use of the measured linear depolarization ratio following the method outlined by [5].

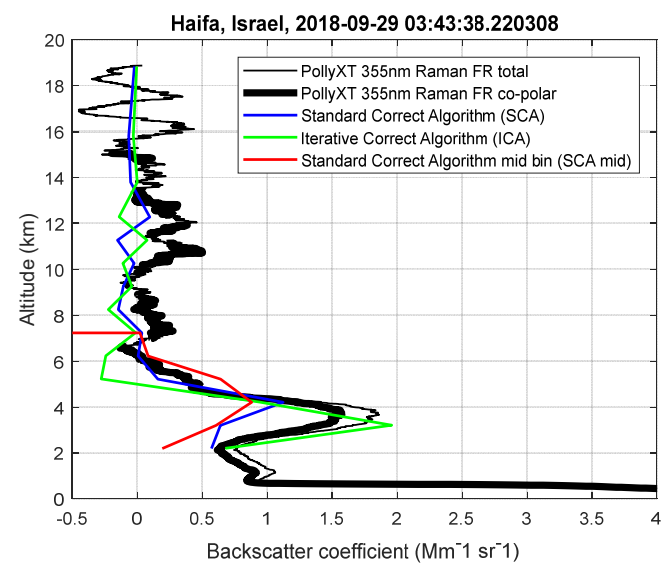

Fig. 4: Comparison of PollyXT at Haifa, Israel during Aeolus overpass on 29 September 2018.

For Aeolus, all three available products, namely the standard correction algorithm (SCA), the 
standard correction algorithm mid bin (using 2 bins to reduce noise) and the iterative correction algorithm (ICA) are shown while knowing that the SCA is the most developed algorithm [7]. Aeolus products below $2 \mathrm{~km}$ are not yet usable due to operational range-bin settings in the early orbit phase. Besides, a good agreement between Aeolus and the ground-based lidar with respect to the co-polar backscatter coefficient is found for this specific case, considering the long averaging length of Aeolus $(87 \mathrm{~km})$ and the distance to the lidar (around $100 \mathrm{~km}$ ). However, also strong deviations have been found for other cases, when e.g. Cirrus are present or the scenes are horizontally heterogeneous. Then the representativeness error of Aeolus has to be taken into account.

\section{CONCLUSIONS AND OUTLOOK}

First results with respect to Aeolus Level 2A (aerosol) and 2B (wind) have been discussed. These comparisons already have yielded valuable insights into the performance of Aeolus. For the Level 2B Rayleigh wind product, a mean bias of $1.82 \mathrm{~m} / \mathrm{s}$ and a scaled median absolute deviation of $4.75 \mathrm{~m} / \mathrm{s}$ were observed. The preliminary investigation of the observed Rayleigh wind bias (wind obtained from backscattering of molecules only) in clear air showed an increase with time. By including updated calibrations in the next product versions, the systematic errors are aimed to be reduced.

Aeolus does not provide valid aerosol products in the lowermost $2 \mathrm{~km}$ yet. Thus, the focus for validation was laid on locations in Israel and the United Arab Emirates. About 10 cases have been found, which are suitable for a direct comparison. For all other overpasses, the large observational integration length $(87 \mathrm{~km})$ of Aeolus together with the distance to the ground-based lidar makes a direct comparison very difficult. Therefore, a change in the focus of interest and the application of new methods needs to be done in future.

\section{ACKNOWLEDGEMENTS}

This work was funded by the German Federal Ministry for Economic Affairs and Energy (BMWi) under grant no. (FKZ) 50EE1721C and 50EE1721A. Authors acknowledge also support through ACTRIS-2 under grant agreement no. 654109 from the European Union's Horizon 2020 research and innovation programme. The lidar data collected from United Arab Emirates are based on work supported by the National Center of Meteorology \& Seismology, Abu Dhabi, UAE, under the UAE Research Program for Rain Enhancement Science. The Analysis is based on preliminary, non-public Aeolus data provided by ESA specifically to $\mathrm{Cal} / \mathrm{Val}$ teams.

\section{REFERENCES}

[1] Illingworth, A.J., D. Cimini, C. Gaffard, M. Haeffelin, V. Lehmann, U. Löhnert, E.J. O'Connor, and D. Ruffieux: Exploiting Existing Ground-Based Remote Sensing Networks to Improve High-Resolution Weather Forecasts. Bull. Amer. Meteor. Soc., 96, 2107-2125, 2015.

[2] Baars, H., et al.: An overview of the first decade of Polly ${ }^{\mathrm{NET}}$ : an emerging network of automated Raman-polarization lidars for continuous aerosol profiling, Atmos. Chem. Phys., 16, 5111-5137, 2016.

[3] European Space Agency ESA, 2008: ADMAeolus Science Report, ESA SP-1311

[4] P. Ingmann and A.G. Straume. ADMAEOLUS mission requirements document. AE-RPESA- SY-001 EOP-SM/2047, 2016.

[5] U. Wandinger et al., Validation of ADMAeolus L2 aerosol and cloud products employing advanced ground-based lidar Measurements (VADAM), ADM-Aeolus Science and CAL/VAL Workshop, 2015.

[6] R. Engelmann et al., The automated multiwavelength Raman polarization and water-vapor lidar PollyXT: the next generation. Atmospheric Measurement Techniques, 9(4):1767-1784, 2016.

[7] Flamant, P. H. et al., ADM-Aeolus L2A Algorithm Theoretical Baseline Document Particle spin-off products, AE-TN-IPSL-GS001 Version 5.5, 2017. 